\title{
Design and Fabrication of a Three-Point Bending Test Rig to Evaluate Strength and Stiffness of I-Beam
}

\author{
Moch Iqbal Rokhim ${ }^{1,2}$, Mohd Shukri Yob ${ }^{1,2, *}$, Mohd Juzaila Bin Abd Latif ${ }^{1,2}$, \\ Fudhail Bin Abdul Munir ${ }^{1,2}$ \\ ${ }^{1}$ Faculty of Mechanical Engineering, Universiti Teknikal Malaysia Melaka, Malaysia
${ }^{2}$ entre for Advanced Research on Energy, Universiti Teknikal Malaysia Melaka, Malaysia
}

Received September 22, 2019; Revised October 17, 2019; Accepted October 27, 2019

Copyright $(2019$ by authors, all rights reserved. Authors agree that this article remains permanently open access under the terms of the Creative Commons Attribution License 4.0 International License

\begin{abstract}
I-beam is widely used as main structures in the automotive and oil and gas industries due to their ability to sustain axial load at very minimum weight. For any structure, the important parameter should put into considerations are strength and stiffness. A Three-point bending test is a well-known method to evaluate the strength and stiffness of a beam. The existing machine to perform a three-point bending test is the Instron ${ }^{\circledR} 5585$ Universal Testing Machines (UTM). However, these machines can only measure specimen within $500 \mathrm{~mm}$ which is insufficient for a longer specimen. In this study, a new design testing rig was proposed to evaluate the strength and stiffness of the longer specimen of I-beam. For this study, the design of the testing rig was evaluated using finite element analysis for 3 different lengths to determine its strength and rigidity. From this analysis, it is found that the proposed design of a testing rig shows satisfactory strength and rigidity for the length of $500 \mathrm{~mm}$ to $1000 \mathrm{~mm}$ when loaded with $10 \mathrm{kN}$ force.
\end{abstract}

Keywords Design and Fabrication, Testing Rig, Three-Point Bending Test, I-Beam, Stress Analysis

\section{Introduction}

I-beam structure steel is widely used in automotive industries and oil and gas industries as main structures due to their ability to sustain high axial load at very minimum weight [1-3]. The width-to-thickness ratio of the flange and web are proven to be the key factors for determining its strength and stiffness [4]. Once the light structure is produced, it can contribute to cost reduction during construction, transportation, and installation [5]. However, there are some drawbacks when using I-beam in engineering applications, such as corrosion and cracking which may lead to high maintenance cost and safety issues [6]. Corrosion is known to lead to a reduction in the thickness of structural members that will indicate the degradation of their mechanical properties [7]. These defects will cause failure to the I-beam at lower than the designated load.

In order to overcome these drawbacks, some researchers proposed using a carbon fiber patch to locally reinforce the I-beam $[5,8,9]$. While other researchers proposed using welding methods to repair the I-beam structure steel [10]. There are also some studies that propose methods to delay the propagation of cracks when the structure is impossible to be replaced or repaired at the time [11,12]. The researchers using the experimental test to evaluate the effect of these methods. One of them was the three-point bending test.

A three-point bending test is known methods used to evaluate the strength and stiffness of a beam $[13,14]$. To conduct a three-point bending test, a testing rig needs to be employed. The main function of the testing rig is fixing the specimen horizontally and applying load on the middle span of the specimen [15]. Commonly, bending test can be performed using the Instron 5585 Universal Testing Machine (UTM). However, the usage of this machine is limited for a specimen which is shorter than $500 \mathrm{~mm}$ in length. From our study, many researchers had tested the I-beam with the length is longer than $500 \mathrm{~mm}[4,16,17]$. Due to that, this research paper will come up with the design and analysis of testing rig which is applicable for the specimen that longer than $500 \mathrm{~mm}$.

So far, there has been little discussion about the standard of a three-point bending testing rig to evaluate the behaviors of I-beam. When evaluating the large or heavy structure, the stiffness of the test rig can be a critical issue to measure the strength and stiffness of the specimen. To accommodate that condition, large carrying frames have to be employed or the testing rig needs to be 
cast to a typical concrete [18-20]. The measurement of deformation can be affected by the stiffness of a testing rig. If the stiffness of testing rig is neglected, there are risk up to $20 \%$ errors in measurement. But if the stiffness is considered, the measurement uncertainty is less than $1 \%$ [18]. Another factor such as loading nose and loading support shall put into consideration to avoid the failure due to stress concentration at the loading nose or supports [21].

\section{Materials and Methods}

In this study, the design of a testing rig was produced using CATIA Software. Then, by using finite element software, the maximum load that can fail the I-beam is identified. This load is applied to the testing rig to evaluate its stress and rigidity. Once this analysis achieved a satisfactory result, the fabrication process can be carried out. The whole process of these works is shown in (Figure 1).

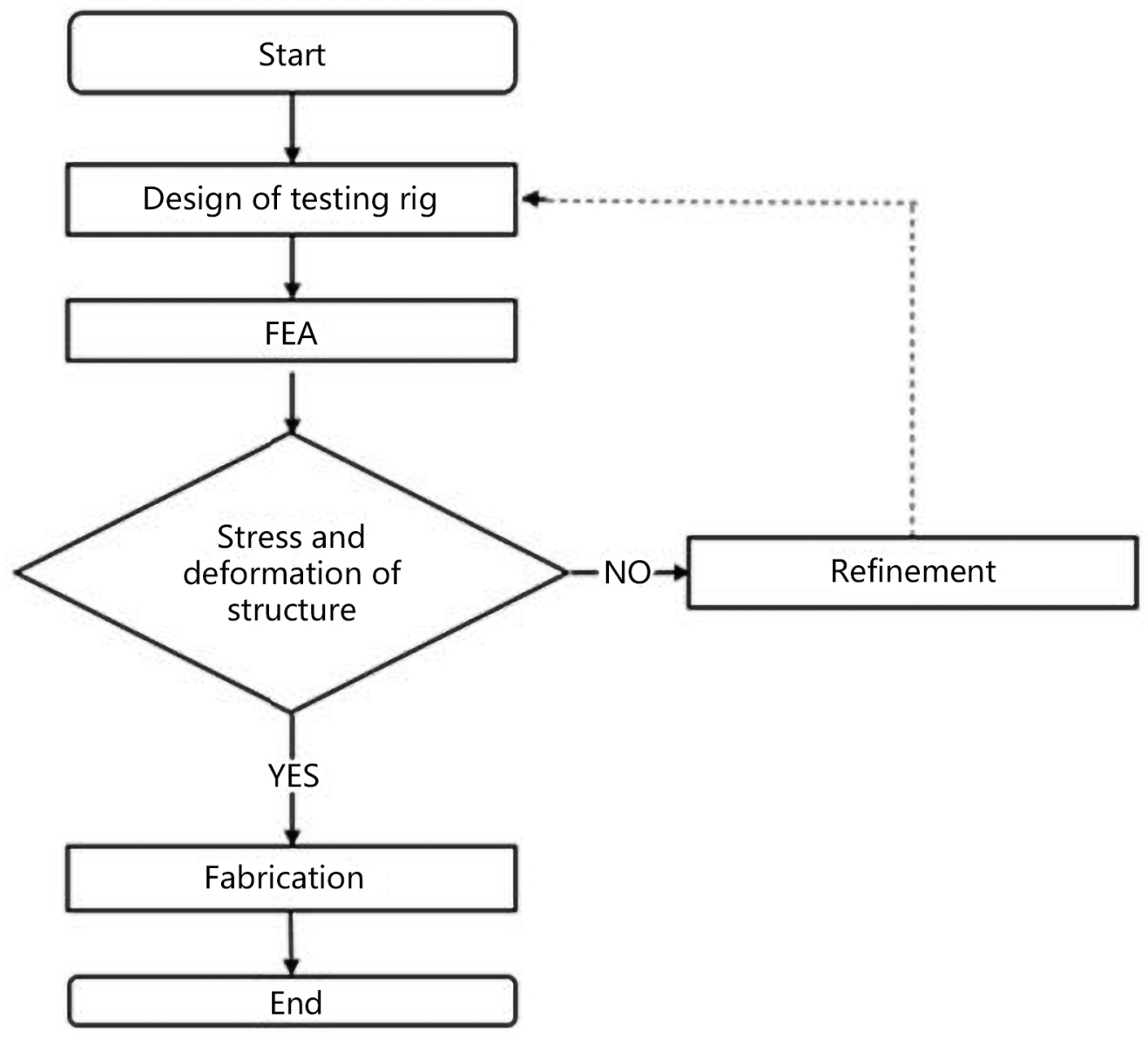

Figure 1. Schematic diagram 


\subsection{Testing Rig Design}

In this research, the maximum size of the I-beam specimen that will be tested is shown in (Figure 2). This specimen was downscale from the $100 \mathrm{~mm} \times 100 \mathrm{~mm}$ sized I-beam which is available in the market. For testing rig, its strength and rigidity must be able to withstand the maximum load that can cause failure to an I-beam specimen.

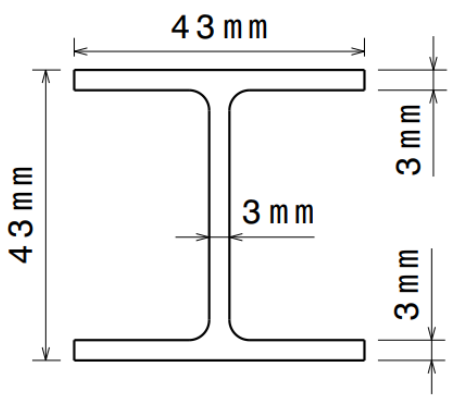

Figure 2. Size of I-beam specimen

Based on the size of the I-beam specimen, the details design of the testing rig is shown in (Figure 3). In this design, I-beam specimen is positioned in the middle of the testing rig and supported by two adjustable blocks. During the testing, the load is applied in the middle of I-beam in a vertically downward direction using a hydraulic jack and measured by a load cell. For measuring the deformation of I-beam, the dial gauge is positioned at the bottom of I-beam and attached to the testing rig.

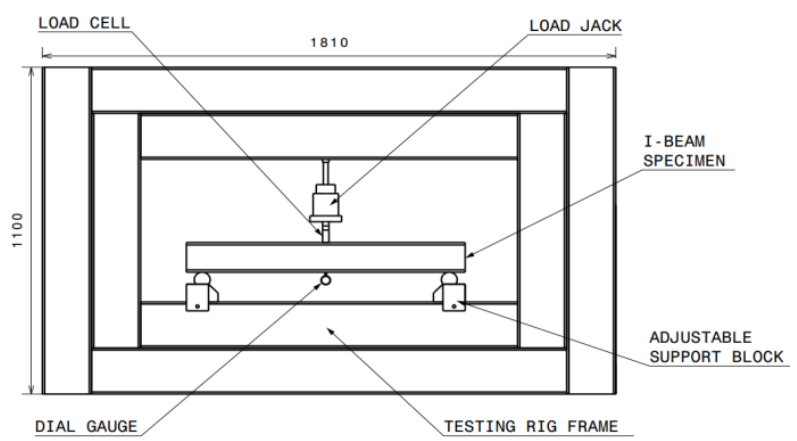

Figure 3. Testing rig design layout

For this design, the main structure of the testing rig is also made of I-beam. The selection of this beam is based on high resistance to the axial load. The size of the I-beam proposed is $105 \mathrm{~mm} \times 155 \mathrm{~mm}$ size with a thickness of 7 $\mathrm{mm}$.

\subsection{Finite Element Analysis (FEA) of the Testing Rig Design}

FEA is carried out for the I-beam and testing rig to evaluate the strength and rigidity to ensure the validity of the result produced. In the analysis, both models will be evaluated for 3 different spans as shown in (Table 1).

Table 1. Support span each cases

\begin{tabular}{|c|c|}
\hline Cases & Support span (L) \\
\hline 1 & $100 \mathrm{~mm}$ \\
\hline 2 & $500 \mathrm{~mm}$ \\
\hline 3 & $1000 \mathrm{~mm}$ \\
\hline
\end{tabular}

The analysis of I-beam is carried out by applying $10 \mathrm{kN}$ load on the middle span of the I-beam specimen while both ends of the I-beam specimen are attached by fixed supports. The boundary condition of the I-beam explained in (Figure 4).

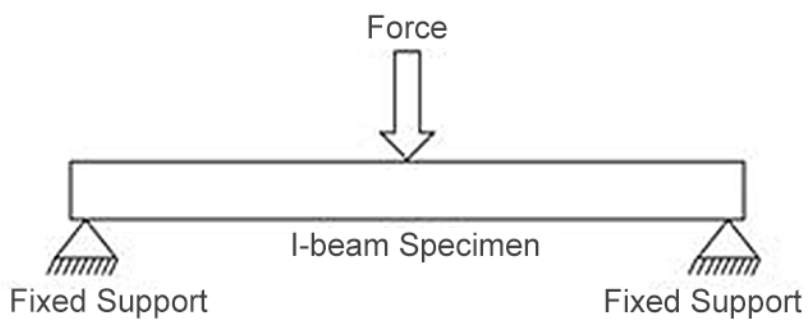

Figure 4. The boundary condition of I-beam

Then, the testing rig is analyzed using the same load used for the I-beam. The loads from the I-beam specimen are applied downward on the two support blocks while the load from the jack is applied upward to the top bar of the testing rig. The overall boundary conditions of the testing rig can be seen in (Figure 5).

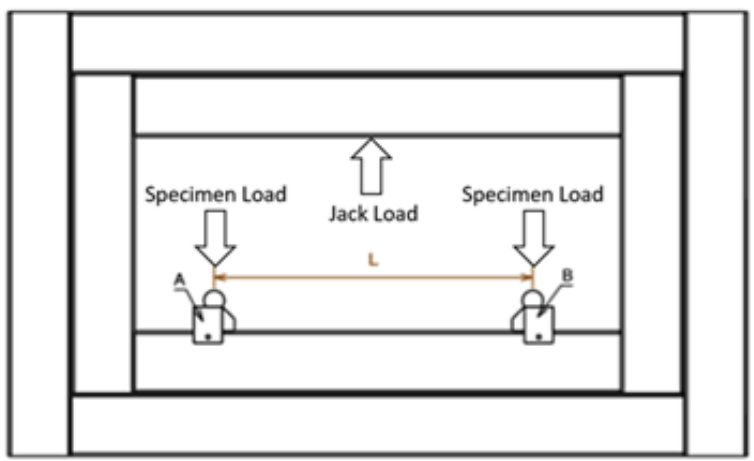

Figure 5. The boundary condition of the testing rig

\section{Results and Discussion}

From FEA, the stress and deformation of models are obtained. The stress results are used to calculate the safety factor to evaluate the strength of the testing rig. Meanwhile, the deformation results are used to calculate the deformation percentage of the testing rig from the I-beam. These percentages are the parameter to evaluate the rigidity of the testing rig. 


\subsection{FEA Result of the I-Beam Model}

FEA result shows both stress and deformation concentration of the I-beam model in each case occurs in the middle of I-beam as shown in (Figure 6).

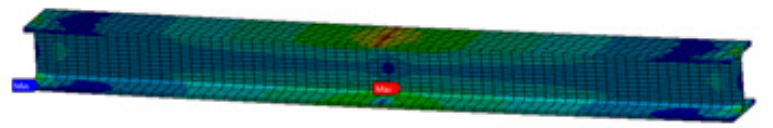

(a)

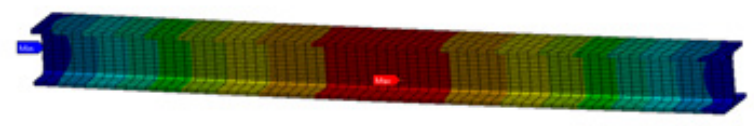

(b)

Figure 6. (a) von Mises stress and (b) Deformation of the I-beam model

The overview FEA result of the I-beam model can be seen in (Table 2). The result shows that in case 1 the stress is below $250 \mathrm{MPa}$, the standard structural steel yield stress. Therefore, the I-beam did not fail in this case. However, in cases 2 and 3 the I-beam was failed under $10 \mathrm{kN}$ load.

Table 2. FEA result of specimen I-beam

\begin{tabular}{|c|c|c|}
\hline Cases & I-beam stress [MPa] & I-beam deformation $[\mathrm{mm}]$ \\
\hline 1 & 204.22 & 0.13 \\
\hline 2 & 371.35 & 1.30 \\
\hline 3 & 607.17 & 11.49 \\
\hline
\end{tabular}

\subsection{FEA Result of the Testing Rig Model}

For case 1, the stress concentration is spread throughout the bottom and the sidebar. The maximum stress that occurs is $18.18 \mathrm{MPa}$ while the maximum deformation is $0.06 \mathrm{~mm}$ as shown in (Figure 7).

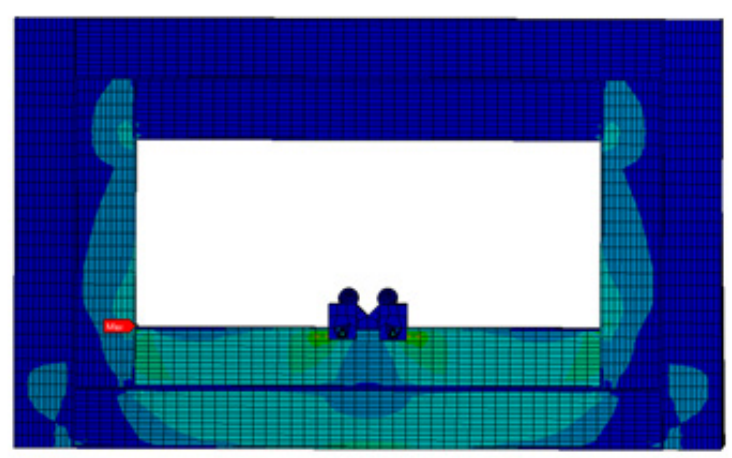

(a)

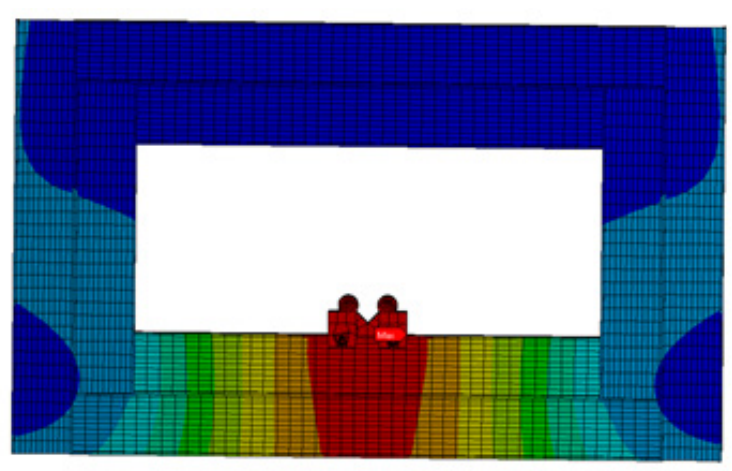

(b)

Figure 7. (a) von Mises stress and (b) Deformation from case 1

Whereas in case 2, the stress distribution concentrates more on the sidebar than in case 1 , with the maximum stress occurring at $16.35 \mathrm{MPa}$. The maximum deformation also occurs in the middle of the bar with a value of 0.05 $\mathrm{mm}$ as shown in (Figure 8).

In case 3, the stress concentrated on both side structure of the testing rig with a maximum stress of $7.89 \mathrm{MPa}$. Meanwhile, the maximum deformation counted at 0.01 $\mathrm{mm}$ as shown in (figure 9).

An overview of the FEA results on the test rig can be seen in (Table 3). From these results, the safety factors and deformation percentages can be calculated.

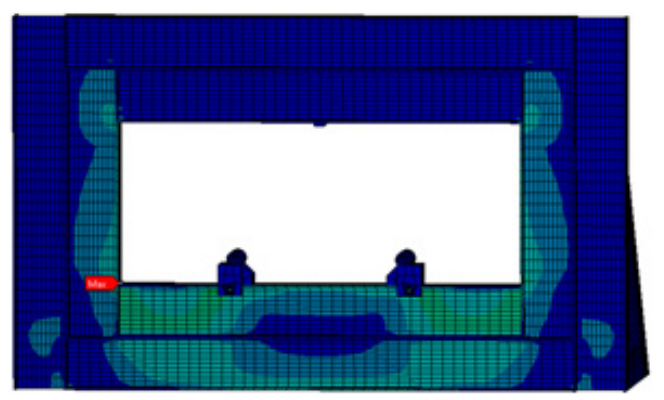

(a)

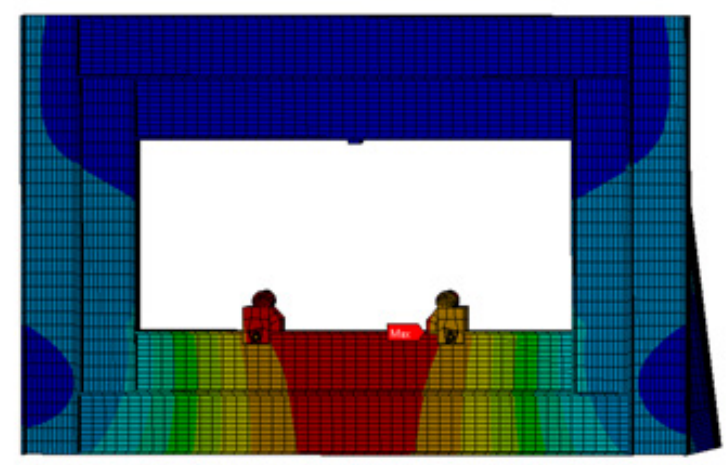

(b)

Figure 8. (a) von Mises stress and (b) Deformation of case 2 


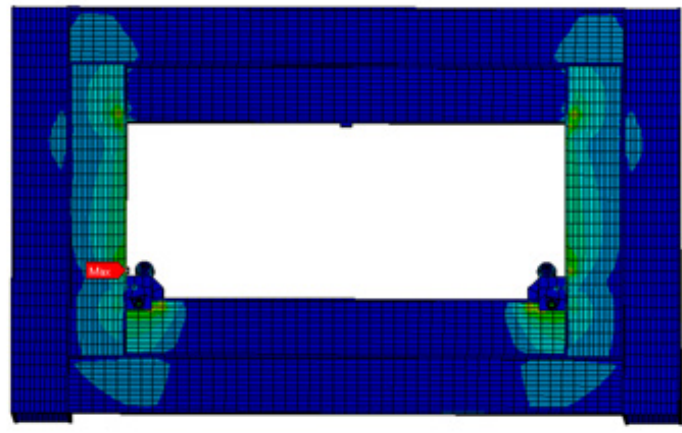

(a)

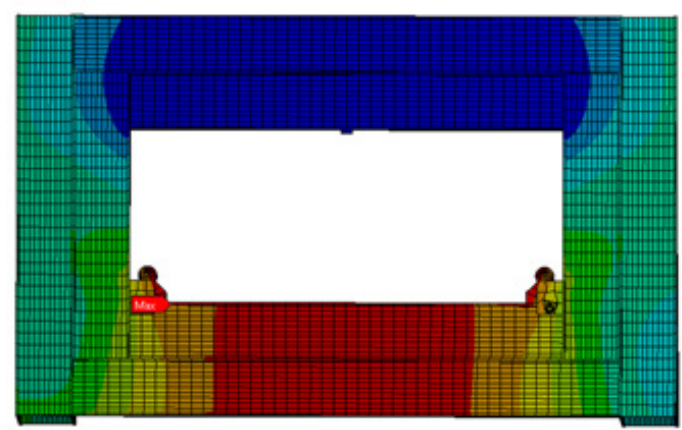

(b)

Figure 9. (a) von Mises stress and (b) Deformation of case 3

An overview of the FEA results on the test rig can be seen in (Table 3). From these results, the safety factors and deformation percentages can be calculated

Table 3. FEA result of the testing rig

\begin{tabular}{|c|c|c|}
\hline Cases & Testing rig stress $[\mathrm{MPa}]$ & Testing rig deformation $[\mathrm{mm}]$ \\
\hline 1 & 18.18 & 0.06 \\
\hline 2 & 16.35 & 0.05 \\
\hline 3 & 7.98 & 0.01 \\
\hline
\end{tabular}

\subsection{Safety Factor}

From the stress results, the safety factor of the testing rig under 3 cases can be calculated. All the results can be seen in (Table 4). From all of the 3 cases, the calculation result obtained more than 10 , it can be concluded that the designed testing rig did not fail even after fully loaded with $10 \mathrm{kN}$ load.

Table 4. Safety factors

\begin{tabular}{|c|c|c|c|}
\hline Cases & $\begin{array}{c}\text { Testing rig stress } \\
{[\mathrm{MPa}]}\end{array}$ & $\begin{array}{c}\text { Yield stress of structure } \\
\text { steel [MPa] }\end{array}$ & $\begin{array}{c}\text { Safety } \\
\text { factor }\end{array}$ \\
\hline 1 & 18.18 & & 13.75 \\
\hline 2 & 16.35 & \multirow{2}{*}{250} & 15.29 \\
\hline 3 & 7.98 & & 31.31 \\
\hline
\end{tabular}

\subsection{Deformation Percentage}

From the deformation results, the deformation percentage of the test rig from the I-beam can be calculated. The calculation results are shown in (Table 5). It was found that in case 1 the deformation percentage is $43 \%$, this result will affect the experiment test. However, in cases 2 and 3 the deformation percentage is less than $4 \%$. Therefore in these two cases, the testing rig can be considered a rigid body.

Table 5. Deformation percentage

\begin{tabular}{|c|c|c|c|}
\hline Cases & $\begin{array}{c}\text { Testing rig } \\
\text { deformation } \\
{[\mathrm{mm}]}\end{array}$ & $\begin{array}{c}\text { Specimen } \\
\text { deformation } \\
{[\mathrm{mm}]}\end{array}$ & $\begin{array}{c}\text { Deformation } \\
\text { percentage [\%] }\end{array}$ \\
\hline 1 & 0.06 & 0.13 & 43.04 \\
\hline 2 & 0.05 & 1.30 & 3.68 \\
\hline 3 & 0.01 & 11.50 & 0.13 \\
\hline
\end{tabular}

\section{Conclusions}

FEA was performed to determine the strength and rigidity of the testing rig when the $10 \mathrm{kN}$ load applied. The FEA results show an excellent result in all cases in terms of safety factors by reaching more than 10 in each case. Due to that, the testing rig can be assumed to be able to sustain a $10 \mathrm{kN}$ load. In terms of testing rig deformation percentage, case 1 produces $43 \%$. This result can affect the experimental test. However, case 2 and 3 shows an excellent result by produced less than $4 \%$. Therefore, the testing rig can be considered as a rigid body. The evidence from this study suggests that the testing rig can be used to evaluate the specimen with the length between $500 \mathrm{~mm}$ to $1000 \mathrm{~mm}$ for $43 \mathrm{~mm}$ x $43 \mathrm{~mm}$ sized I-beam or smaller under $10 \mathrm{kN}$ load. On the basis of this evidence, a testing rig is fabricated following the proposed design.

\section{Acknowledgements}

In this paper, testing rig design for a three-point bending test of thin-walled structural steel was created in the framework of the research study at University Teknikal Malaysia Melaka (UTeM). The authors would like to thank Applied Mechanical Design laboratory UTeM for the support throughout this study. The authors gratefully acknowledge UTeM that provided access to use the pictures and all journals that provide open access articles that supported this work.

\section{REFERENCES}

[1] J. Abry, C. Mittelhaeuser, S. Wolf, and D. Turlier, "Enhanced fatigue structural stress analysis of a heavy vehicle seam welded steel chassis frame: FEA model preparation, weld model description, fatigue stress calculation and correlation with 10 year operating experience," Procedia Eng., vol. 213, no. 2017, pp. 539-548, 2018. 
[2] Y. B. Sudhirsastry, Y. Krishna, and P. R. Budarapu, "Parametric studies on buckling of thin walled channel beams," Comput. Mater. Sci., vol. 96, no. PB, pp. 416-424, 2015.

[3] D. Lanc, T. P. Vo, G. Turkalj, and J. Lee, "Buckling analysis of thin-walled functionally graded sandwich box beams," Thin-Walled Struct., vol. 86, pp. 148-156, 2015.

[4] X. Cheng and Y. Chen, "Ultimate strength of H-sections under combined compression and uniaxial bending considering plate interaction," J. Constr. Steel Res., vol. 143, pp. 196-207, 2018.

[5] A. H. Keykha, "Investigation of load Increment in Hollow Steel short and slender Columns Strengthened using CFRP," vol. 31, pp. 163-169, 2015.

[6] K. Y. Ning, L. Yang, H. Y. Ban, and Y. N. Sun, "Experimental and numerical studies on hysteretic behaviour of stainless steel welded box-section columns," Thin-Walled Struct., vol. 136, no. 2018, pp. 280-291, 2019.

[7] J. Jelovica, J. Romanoff, and H. Remes, "In fl uence of general corrosion on buckling strength of laser-welded web-core sandwich plates," JCSR, vol. 101, pp. 342-350, 2014.

[8] T. CHEN, Q.-Q. YU, X.-L. GU, and X.-L. ZHAO, "Study on Fatigue Behavior of Strengthened Non-Load-Carrying Cruciform Welded Joints Using Carbon Fiber Sheets,” Int. J. Struct. Stab. Dyn., vol. 12, no. 01, pp. 179-194, 2012.

[9] P. Colombi, A. Bassetti, and A. Nussbaumer, "Crack growth induced delamination on steel members reinforced by prestressed composite patch," Fatigue Fract. Eng. Mater. Struct., vol. 26, no. 5, pp. 429-437, 2003.

[10] Y. Wang, J. A. Wharton, and R. A. Shenoi, "Ultimate strength analysis of aged steel-plated structures exposed to marine corrosion damage : A review," Corros. Sci., vol. 86, pp. 42-60, 2014.

[11] Z. G. Xiao, X. L. Gu, X. L. Zhao, T. Chen, and Q. Q. Yu, "Fatigue behaviour of CFRP strengthened steel plates with different degrees of damage," Thin-Walled Struct., vol. 69, pp. 10-17, 2013.

[12] S. M. J. Razavi, M. R. Ayatollahi, C. Sommitsch, and C. Moser, "Retardation of fatigue crack growth in high strength steel S690 using a modified stop-hole technique," Eng. Fract. Mech., vol. 169, pp. 226-237, 2017.

[13] Y. Q. Wang, L. Zong, R. X. Zhu, X. Y. Liu, and Y. J. Shi, "Behavior of I-section steel beam welding reinforced while under load,” J. Constr. Steel Res., vol. 106, pp. 278-288, 2015.

[14] S. Kang, B. Yang, Y. Zhang, M. Elchalakani, and G. Xiong, "Global buckling of laterally-unrestrained Q460GJ beams with singly symmetric I-sections," J. Constr. Steel Res., vol. 145, pp. 341-351, 2018.

[15] N. Nagabhooshanam, S. Baskar, P. K. Nagarajan, and K. S. Kumar, "Design and Fabrication of Fatigue Test Rig and Preliminary Investigation on Flax Composite Beam," Mater. Today Proc., vol. 5, no. 5, pp. 11771-11779, 2018.

[16] M. I. Kabir and A. K. Bhowmick, "Applicability of North American standards for lateral torsional buckling of welded I-beams,” J. Constr. Steel Res., vol. 147, pp. 16-26, 2018.
[17] X. Cheng, D. Duan, and Y. Chen, "Sectional constitutive model for the thin-walled steel H-section beam-column element," J. Constr. Steel Res., vol. 156, pp. 202-214, 2019.

[18] G. Previati, M. Gobbi, and G. Mastinu, "Measurement of the mass properties of rigid bodies by means of multi-filar pendulums - Influence of test rig flexibility," Mech. Syst. Signal Process., vol. 121, pp. 31-43, 2019.

[19] M. S. Yob, S. Mansor, and R. Sulaiman, "Finite Element Modelling to Predict Equivalent Stiffness of 3D Space Frame Structural Joint Using Circular Beam Element," Appl. Mech. Mater., vol. 431, pp. 104-109, 2013.

[20] M. S. Yob, S. Mansor, and R. Sulaiman, "Joint Stiffness of 3D Space Frame Thin Walled Structural Joint Considering Local Buckling Effect,” Appl. Mech. Mater., vol. 660, pp. 773-777, 2014

[21] A. International, "D 6272 - 02 Standard Test Method for Flexural Properties of Unreinforced and Reinforced Plastics and Electrical Insulating Materials by Four-Point Bending," pp. 1-9, 2002. 